\title{
Estimating the environmental attractions of rural tourism lodging units in La Gomera island, Spain
}

\author{
Yolanda Santana-Jiménez ${ }^{1 *}$, Juan M.Hernández ${ }^{1,2}$ and Rafael Suárez-Vega ${ }^{1,2}$
}

Received: 15/07/2012 Accepted: 30/01/2013

\footnotetext{
${ }^{1}$ Department of Quantitative Methods in Economics, University of Las Palmas de Gran Canaria, Spain

${ }^{2}$ Institute of Tourism and Sustainable Development (TIDES), c/ Saulo Torón, s/n, 35017 Spain

* Corresponding author: tel: 34-928-458228; email: jhernandez@dmc.ulpgc.es
}

\begin{abstract}
The environmental characteristics compound one of the main attractions of the tourism developed in rural areas. In this line, this paper seeks to identify the most relevant environmental attributes valued by the rural tourism market in La Gomera Island, Spain. The geographic peculiarities (climate and landscape) of this island make it an exceptional case study to analyse the role of the environmental factors in rural tourism. A hedonic price model has been estimated to obtain a quantitative measure of the relative weight of rural house attributes in the rental price. Geographical Information System (GIS) and Spatial Econometric techniques have been applied to compute environmental variables and get accurate estimations of the model, respectively. Results show the relevance of the climate conditions in the surroundings of the house for the rural tourism lodging market in La Gomera, and allow formulating some recommendations to public and private authorities in the design of promotional and investment policies in the sector. A similar procedure can be applied to other rural tourist destinations, where the required socioeconomic and geographic information is available.
\end{abstract}

(C) 2013 International University College. All rights reserved

Keywords: Rural houses, hedonic pricing, environment, GIS, Canary Islands

Citation: Jiménez, Y., J. Hernández, R. Vega (2013) Estimating the environmental attractions of rural tourism lodging units in La Gomera island, Spain. European Journal of Tourism Research 6(2), pp. $132-140$

\section{Introduction}

The geographical environment where the rural tourism is developed enjoys some peculiarities that characterise its main tourist attractions. According to Roberts and Hall (2003), its major features are: a) low population density; b) land use and economy based mainly on traditional agricultural and forestry industries; and c) traditional social structures. These factors model the site where the tourist activity takes place and where the lodging supply is located. Visitors take into account and weight the factors derived from the above characteristics when deciding in which rural tourist area to 
stay. In order to help managers and authorities to define the promotional policy for enhancing rural tourism, the process of identifying which factors are most valued by the market becomes a relevant task.

Environmental variables represent a central role in rural tourism, as was shown by Sharpley and Sharpley (1997), who sustain that "rural environment is the prime attraction of the countryside", including "the sense of space and freedom and the opportunity for peace and relaxation". According to some empirical studies, variables that represent landscape diversity, as well as its location, that is, whether it is sited in an urban area or not, influence positively on the price of the house (Geoghegan et al., 1997, Bastian et al., 2002, Santana-Jiménez et al., 2011). Other studies for the specific case of the rural tourism in Spain highlight that search of tranquility is one of the main motivations of the rural tourist (Pulido-Fernández, 2008), jointly to gastronomy or contact with rural environment.

The present paper aims to identify the environmental factors that are most valued by the rural tourism lodging market in the island of La Gomera, Canary Islands. Rural tourism in the Canary Islands has experienced a rapid increase in the last decade (from a rural lodging supply in the archipelago of 414 units in 2001 to 681 in 2011). Additionally, the volume of visitors has increased by $137 \%$ since 2001 . La Gomera is characterized by the richness of its landscapes and flora and its peaceful atmosphere. In this island, although its economy was based from the conquest (XV century) on the primary sector (agriculture, animal husbandry and fishing), tourism has become a relevant sector in recent years as a consequence of the improvement of the communication networks via port and airport. The initial supply was located in hotels near the coast, and later the offer of rural lodgings has increased significantly. Therefore, based on the above characteristics, the island of La Gomera is selected as an adequate destination to analyse the role of environmental factors in rural tourism.

In order to carry out the study purposes, a hedonic pricing model is applied to rural tourism lodging market in the island. Geographical Information Systems (GIS) will be used to define the specific environmental variables for each house. Attributes such as landscape diversity, altitude or the orientation (windward or leeward) of the house are some of the environmental factors that can be estimated by GIS techniques and subsequently included in the hedonic price model. Additionally, the application of spatial econometric techniques will allow obtaining reliable results.

\section{Methodology}

The hedonic pricing model assumes that the price $p$ of a good or product is influenced by a set of characteristics $\left(x_{1}, x_{2}, \ldots, x_{k}\right)$ through the following relationship: $p=f\left(x_{1}, x_{2}, \ldots, x_{k}\right)$. Attributes may not be explicitly valued by the market, but its price is implicitly included in the price of the good. In this paper, the good is the rural house, and its rental price is determined by the different attributes which cannot be offered separately.

The theoretical fundaments of the hedonic price models can be found in Rosen (1974). In general, these models are valid when the good is commercialised in a unique market in perfect competition, where producers and consumers have homogeneous information of its attributes. These conditions can be assumed for the case study, since rural houses in the destination are currently supplied through web pages where location, environmental characteristics and facilities are described. This fact allows a wide and diverse demand, while producers are small owners with limited capacity to fix prices.

The use of GIS is proposed for the measurement of the characteristics of the rural house. GIS are a set of computer software that allows collecting, representing and manipulating geo-referenced information. This means that it does not only permit the visualization of the information in a map, but also can be used to compute the numerical values of spatially distributed variables. Although the first GIS empirical works appeared in the sixties, its use has experienced a dramatic increase in the last decade due mainly to two reasons: on the one hand, the computer advances have facilitated the 
creation of GIS software able to manage large data sets required to handle spatial data base; on the other hand, the storage of GIS information has been recently promoted by diverse organizations, such as public administrations, who are aware of its relevance both for management and research purposes.

Once the variables $\left(x_{1}, x_{2}, \ldots, x_{k}\right)$ representing the attributes of a hedonic price function (1) are computed, the functional form $f(\cdot)$ is estimated through usual econometric techniques. Nevertheless, the spatial character of the sample in this study (rural houses for rent) makes classical econometric estimation methods incorrect. To overcome these deficiencies, econometric techniques that incorporate the existence of spatial correlation have been developed (Anselin, 2005). They consist of whether including the endogenous variable as regressor (spatial lag model) or the error as a regressor of itself (error lag model). In general, the model to be estimated is the following:

$\ln (p)=\alpha+\rho W \ln (p)+X^{\prime} \beta+u$

Where $u=\lambda W u+\varepsilon, \varepsilon \sim N\left(0, \sigma^{2} I_{n}\right)$.

The vector $X_{m \times n}$, with $m \geq k$ and $n$ the sample size, includes the independent variables $\left(x_{1}, x_{2}\right.$, $\left.\ldots, x_{k}\right)$ and their functional expressions that are considered as possible regressors. Vector $\beta_{m \times 1}$ measures the influence of vector $X$ over the rental prices $p_{n \times 1}$, while $\alpha_{n \times 1}$ is a constant vector with identical components that represents the intercept. The influence of neighbouring rental prices on a specific house is weighted through a matrix $W_{n \times n}$, and the parameter $\rho$ shows the degree of interdependency among the observed prices. Error $u_{n \times 1}$ follows a spatial lag process, that is, it is explained by the lag coefficient $\lambda$ weighted by matrix $W$.

Matrix $W_{n \times n}$ is built by row standardising a previous matrix of order $n$ with components $w_{i i}^{\prime}=0$ and $w_{i j}^{\prime}=1$ or 0 depending on whether house $i$ is connected with house $j$ or not, with $i \neq j, i, j \in\{1,2, \ldots n\}^{1}$. Elements of $W_{n \times n}$ are $w_{i j}=w_{i j}^{\prime} / \sum_{j=1}^{n} w_{i j}^{\prime}$. Thus, by including matrix $W$ in model (1), rental prices in the surroundings of a house are weighted. The higher the number of houses within the surroundings of a house, the lower their weight is in the estimation of the price of the specific house.

The estimations for parameters $\rho$ and $\lambda$ determine four possible models: a) $\rho=\lambda=0$ corresponds to Least Squares estimation (LS); b) $\rho \neq 0, \lambda=0$ is a spatial lag model; c) $\rho=0, \lambda \neq 0$ is an error lag model; and finally, d) $\rho \neq 0, \lambda \neq 0$ is a mix model considering both spatial lag and error lag models.

Before applying model (1), the existence of spatial correlation in the dependent variable must be tested. For this purpose, the Moran's I statistics is estimated, defined by the formula,

$$
I=\frac{n}{\sum_{j=1}^{n} \sum_{i=1}^{n} w_{i j}} \cdot \frac{\sum_{j=1}^{n} \sum_{i=1}^{n} w_{i j}\left(p_{i}-\bar{p}\right)\left(p_{j}-\bar{p}\right)}{\sum_{i=1}^{n}\left(p_{i}-\bar{p}\right)^{2}},
$$

where $\bar{p}$ is the average price of the sample. Statistics I follows a Normal distribution with zero mean and represents an approximation to the correlation between the price of a specific house and the prices from its neighbouring houses weighted according to the definition of matrix $W$. The rejection of the null hypothesis $(I \neq 0)$ (acceptance of the alternative hypothesis) shows the existence of spatial correlation and justifies the application of the general model (1).

Although the above test informs about the existence of spatial dependence, it does not discriminate against options. Some set of tests that compare the estimations obtained with the classical model (OLS) to the spatial ones will be applied. A detailed explanation of these tests is found in Anselin (2005).

\section{Case study \\ Destination}

The methodology is applied to analyse the most relevant environmental attributes, as well as other factors, that influence on the rural tourism accommodation market in La Gomera. The island has a small surface $\left(372 \mathrm{~km}^{2}\right)$ but a considerable altitude (1487 $\mathrm{m}$ above sea level), 
and is located in the Canary archipelago. Due to its volcanic origin, it presents a rough topography, with deep valleys and steep slopes. The landscape is determined by the presence of the trade winds, which whip the North side of the island and are the cause of two different climatologies. Windward slope represents one third of the surface of the island. It is characterised by the presence of dense clouds above $800 \mathrm{~m}$, frequent rains, and mild temperatures. The land above $800 \mathrm{~m}$ is covered by dense vegetation that needs humidity, and in the highest peaks the Garajonay National Park is located, including a macaronesian forest of great ecological value. The Park was declared world heritage by the UNESCO in 1986. On the contrary, the leeward slope enjoys frequent sunny days all the year round, and arid areas with scarce vegetation, especially bushes, characterise its landscape. In both slopes altitude affects the climate conditions with a decrease of the temperature and higher humidity.
The original landscape has been modelled by human activity. Windward slopes are occupied by crop lands, previously cane and nowadays banana trees, which are part of the tourist interests. As a relevant fact, 63000 tourists visited the island in 2011, 53000 of which were foreigners, mostly German. The number of beds offered by hotels is 1982, while the nonhotel accommodation offer is 3443 beds, the latter including rural lodgings and apartments. The promotion of the island as a quiet place with high ecological value has led to an increase of resident population lately. Nowadays, the island has a population of 23000 inhabitants, from which $5000(22 \%)$ are foreigners.

\section{Variables}

In order to estimate the model, a sample of 63 rural houses was extracted from two web sites which supply rural lodging: the Canary association of rural tourism (ACANTUR) and TopRural. Figure 1 shows a map of the island

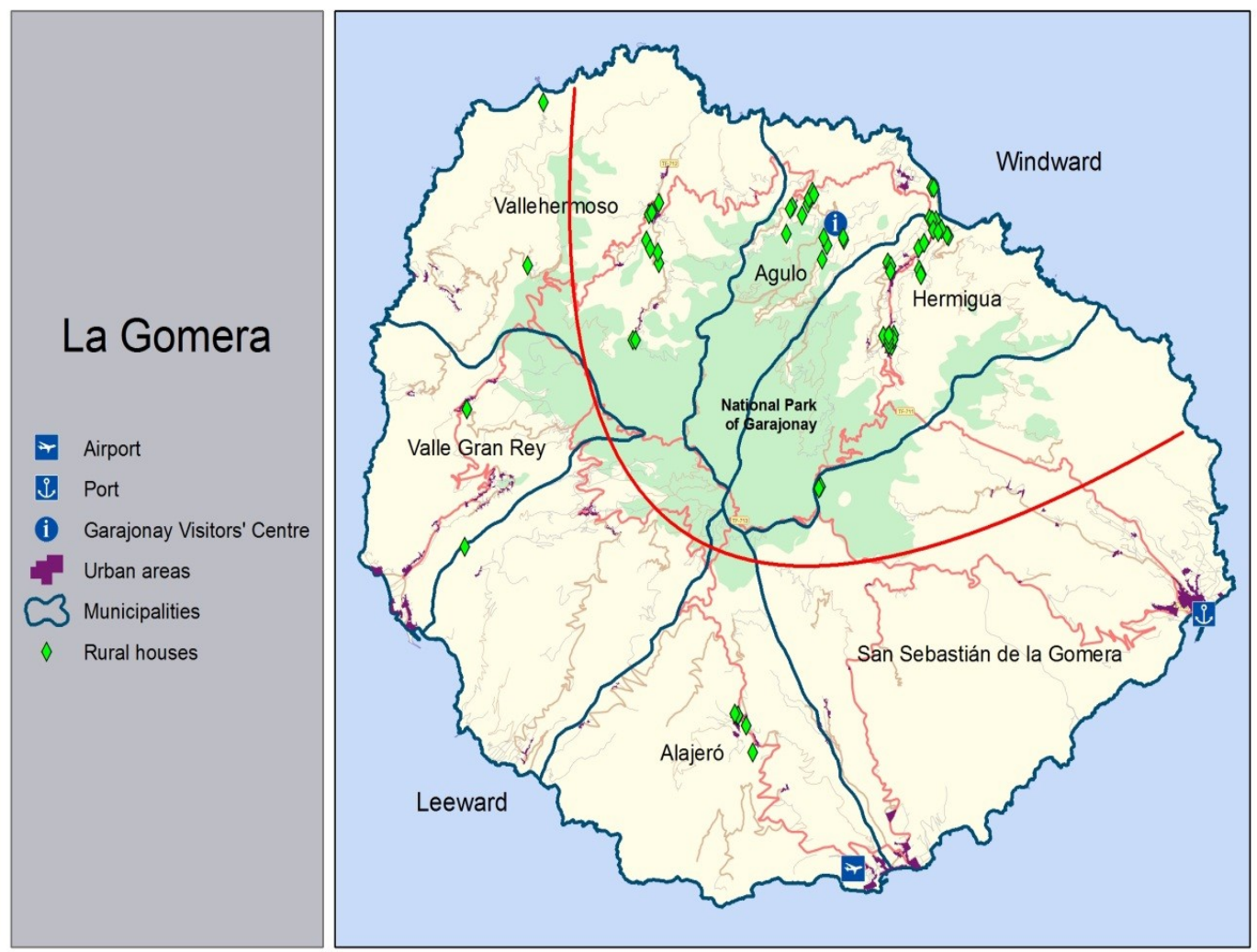

Figure 1. Map of La Gomera Island showing the rural lodgings, main roads (pink), windward and leeward slopes (red line), and other points of interest. 
indicating the geographical location of the rural houses analysed in this study, together with other environmental and spatial indicators. Table 1 shows the variables included in the hedonic prices model for the rural houses market in La Gomera. According to Geoghegan et al. (1997), White and Mulligan (2002) and Thrane (2005), attributes can be classified in three groups: a) structural, which include facilities and physical characteristics of the rural house, such as number of rooms, TV, garden, etc.; b) environmental, which include those variables describing characteristics of the surroundings of the house, such as landscape, climate, type of location (urban or rural), etc.; and c) spatial, which consider those factors related to geographical location of the house (coordinates), distance to interest points, altitude, population density within a radius from the house, etc.

The variables in this study were chosen considering the attributes most frequently valued by similar markets from other regions, and also the particularities of the rural tourism in the island. Therefore, the structural variables selected are the number of beds in the house and other two informing about facilities, such as the existence of barbecue or fireplace.

Through the software program ArcGIS, the location of the houses included in the study was geo-referenced and spatial and environmental variables, corresponding to each lodging, were estimated. The required geographical information was taken from GRAFCAN (Cartográfica de Canarias, S.A.), the main provider in the Canary Islands. The maps used in this study are the following:

a) Map of land use in La Gomera in year 2002. Scale 1:25.000.

b) Road map of the island.

c) Map of the rural houses in the island.

d) Map of the distribution of the population

Table 1. Notation, definition and descriptive statistics of the variables corresponding to $n=63$ rural houses in La Gomera.

\begin{tabular}{|c|c|c|c|c|c|}
\hline Variables & Definition & Mean & S.D. $^{a}$ & Min. & Max. \\
\hline Price & Price per night for 2 persons (euros) & 54.06 & 13.49 & 40 & 115 \\
\hline \multicolumn{6}{|c|}{ Structural Variables } \\
\hline Beds & Number of beds in the house & 4.25 & 5.13 & 2 & 36 \\
\hline TVSat & Satellite TV in the house ( $1=y e s, 0=$ no) & 0.32 & 0.47 & 0 & 1 \\
\hline Cot & Cot in the house $(1=y e s, 0=$ no $)$ & 0.87 & 0.34 & 0 & 1 \\
\hline Washing $M$. & $\begin{array}{l}\text { Washing machine in the house }(1=y e s, \\
0=\text { no) }\end{array}$ & 0.67 & 0.48 & 0 & 1 \\
\hline Barbecue & Barbecue in the house $(1=y e s, 0=$ no $)$ & 0.34 & 0.48 & 0 & 1 \\
\hline $\begin{array}{l}\text { Fireplace } \\
\text { Environmental }\end{array}$ & Fireplace in the house $(1=y e s, 0=$ no $)$ & 0.047 & 0.21 & 0 & 1 \\
\hline Urban & Land use ( $1=$ urban, $0=$ rural) & 0.507 & 0.503 & 0 & 1 \\
\hline Divind_1km & Diversity index within 1 km & 0.610 & 0.141 & 0.127 & 0.891 \\
\hline Divind_3km & Diversity index within $3 \mathrm{~km}$ & 0.636 & 0.180 & 0.235 & 0.884 \\
\hline Altitude & Altitude $(\mathrm{m})$ & 397.25 & 294.54 & 20 & 1.161 \\
\hline $\begin{array}{l}\text { Windward } \\
\text { Spatial variables }\end{array}$ & Slope ( $1=$ windward; $0=$ leeward $)$ & 0.841 & 0.368 & 0 & 1 \\
\hline Airpkm & Distance to the airport $(\mathrm{km})$ & 31.93 & 7.95 & 8.59 & 43.71 \\
\hline Portkm & Distance to the port $(\mathrm{km})$ & 26.04 & 8.59 & 16.12 & 50.00 \\
\hline Garajonaykm & Distance to V.C. ${ }^{\mathrm{b}}$ Garajonay (km) & 10.96 & 6.74 & 0.52 & 31.89 \\
\hline Coastkm & Distance to nearest coast $(\mathrm{km})$ & 5.48 & 3.78 & 0.52 & 13.29 \\
\hline CoastMeankm & Average distance to coastal points $(\mathrm{km})$ & 27.62 & 1.60 & 23.58 & 34.55 \\
\hline Pop_1km & Population at $1 \mathrm{~km}$ from the house by road & 266.78 & 215.55 & 0 & 907.59 \\
\hline Pop_3km & $\begin{array}{l}\text { Population at a } 3 \mathrm{~km} \text { from the house by } \\
\text { road }\end{array}$ & 1071.4 & 740.04 & 5.29 & 3.219 .67 \\
\hline
\end{tabular}

${ }^{a}$ Standard deviation.

${ }^{\mathrm{b}}$ Visitors Centre. 
centres (from Canary Statistical Institute) and their population census in year 2008.

From these sources, variable Urban was estimated, which is a dummy that shows whether the house is located in a residential area or not. The Diversity index represents the diversity of the land uses that exist around the house. For the calculation of this index several environmental uses (forests, vegetation, beaches, etc.) related to infrastructures (roads, health services, tips, etc.) and to the developed activity (residential, agricultural or industrial areas, etc.) have been considered. The formula proposed by Bastian et al. (2002) was chosen for the calculation of this index. The variable ranges from 0 to 1 , and highest values show relevant diversity in the surroundings of the rural house. The diversity indexes have been computed in this study considering radii of 1 and $3 \mathrm{~km}$.

As mentioned above, trade winds play a fundamental role in the island's climate. The location of the house with respect to these trade winds (windward or leeward) and its altitude above sea level influence on temperature, rainfall and humidity in the surroundings of the house. Thus, two variables have been estimated to proxy the climate: Altitude, which represents the altitude of the house with respect to the sea level, taken from the viewer from IDE-Canarias, a web tool supplied by GRAFCAN; and Windward, a dummy variable that indicates whether the house is windward oriented or not. Additionally, the multiplicative variable Altitude*Windward was added to the model, allowing the different effect of altitude whether the house is located in windward or in leeward.

Some of the spatial variables selected represent the level of isolation of the rural house as an indicator of tranquillity. Thus, the distance to the main transport points of the island (port and airport) has been computed. Other variable that represents isolation is the population within a radius of 1 or $3 \mathrm{~km}$ from the house. The distance by road was preferred to the Euclidean distance due to the rough orography of the island. Some additional variables that measure the distance to tourist sites have also been considered, such as the Garajonay visitors' Centre, the nearest beach from the house and the average distance to the beaches.

\section{Statistical results}

The software Space Stat has been used to carry out the econometric analysis. The results of the hedonic price model are shown in Table 2. Initially, an OLS model has been estimated, without considering the existence of spatial correlation (M1). Two dummy variables were included in the estimation corresponding to outliers (D8 and D41). According to the previous applications of hedonic price models to rural tourism, some structural variables such as Beds (number of beds in the house) or the existence of fireplace influence positively on the price. The model also shows that houses located in urban areas have lower rental prices than those sited in rural ones. Specifically, taking into account the interpretation of the dummy variables in a log-linear model, houses located in urban areas have a rental price $13.9 \%$ lower than those placed in rural areas $\left(e^{-0.15}-1 \approx-0.139\right)$. Notice that among the initially proposed variables in Table 1 , some of them are not significant in the final specification of the model, after the inclusion of the outliers; this is the case of some environmental ones (Divind_1 km, Divind_3km), as well as the spatial variables about population density (Pop_1km, Pop_3km).

The spatial dependence of prices may add relevant information to the previous model. In order to test the existence of spatial autocorrelation among the rental prices of the rural houses, the Moran's I test was computed. Different alternatives for the weight matrix were assumed, by considering different radii from the rural house, as well as different numbers of neighbouring houses. The weight matrix that considered the influence of the 2 nearest neighbours showed the most significant spatial dependence. The statistics has a value of $I=0.28$, significant at $1 \%$, showing a positive spatial correlation among the rental prices and pointing out the convenience of estimating the spatial econometric model (1). In order to determine the most adequate spatial model, a sequence of spatial diagnostic tests was performed from the classical model (M1), using 
Table 2. Estimation of the parameters of model (1): (M1) OLS estimation $(\rho=\lambda=0)$; (M2) error spatial model $(\lambda \neq 0, \rho=0)$, considering $W$ the spatial weight matrix that connects the two nearest neighbours from each house; (M3) spatial lag model $(\lambda=0, \rho \neq 0)$, considering $W$ the spatial weight matrix that connects the two nearest neighbours from each house.

\begin{tabular}{|c|c|c|c|}
\hline $\begin{array}{l}\text { Dependent variable: } \\
\text { Log(Price) }\end{array}$ & $\frac{\mathrm{M} 1}{\mathrm{OLS}}$ & $\begin{array}{l}\mathrm{M} 2 \\
\text { Weight matrix: } \\
2 \text { nearest neighbours }\end{array}$ & $\begin{array}{l}\mathrm{M} 3 \\
\text { Weigh matrix: } \\
2 \text { nearest neighbours }\end{array}$ \\
\hline$\rho$ & & & $\begin{array}{l}0.24^{* *} \\
(0.01)\end{array}$ \\
\hline$\lambda$ & & $\begin{array}{l}0.33^{* * *} \\
(0.00)\end{array}$ & \\
\hline D8 & $\begin{array}{l}0.75^{\star * \star} \\
(0.00)\end{array}$ & $\begin{array}{l}0.78^{* \star *} \\
(0.00)\end{array}$ & $\begin{array}{l}0.80^{* * *} \\
(0.00)\end{array}$ \\
\hline$D 41$ & $\begin{array}{l}0.69^{* * *} \\
(0.00)\end{array}$ & $\begin{array}{l}0.63^{* * *} \\
(0.00)\end{array}$ & $\begin{array}{l}0.65^{\star \star *} \\
(0.00)\end{array}$ \\
\hline Intercept & $\begin{array}{l}3.57^{* \star *} \\
(0.00)\end{array}$ & $\begin{array}{l}3.57^{* \star *} \\
(0.00)\end{array}$ & $\begin{array}{l}2.64^{* * *} \\
(0.00)\end{array}$ \\
\hline Beds & $\begin{array}{l}0.014^{\star * *} \\
(0.00)\end{array}$ & $\begin{array}{l}0.013^{* * *} \\
(0.00)\end{array}$ & $\begin{array}{l}0.012^{* * *} \\
(0.00)\end{array}$ \\
\hline Fireplace & $\begin{array}{l}0.21^{* *} \\
(0.01)\end{array}$ & $\begin{array}{l}0.21^{* * *} \\
(0.00)\end{array}$ & $\begin{array}{l}0.20^{* * *} \\
(0.00)\end{array}$ \\
\hline Urban & $\begin{array}{l}-0.15^{* * *} \\
(0.00)\end{array}$ & $\begin{array}{l}-0.12^{* * *} \\
(0.00)\end{array}$ & $\begin{array}{l}-0.12^{* * *} \\
(0.00)\end{array}$ \\
\hline Altitude & $\begin{array}{l}0.00043^{*} \\
(0.05)\end{array}$ & $\begin{array}{l}0.0003^{*} \\
(0.06)\end{array}$ & $\begin{array}{l}0.0004^{* *} \\
(0.02)\end{array}$ \\
\hline Windward & $\begin{array}{l}0.48^{* * *} \\
(0.00)\end{array}$ & $\begin{array}{l}0.46^{* \star *} \\
(0.00)\end{array}$ & $\begin{array}{l}0.44^{\star * *} \\
(0.00)\end{array}$ \\
\hline Altitude*Windward & $\begin{array}{l}-0.0007^{* * *} \\
(0.00)\end{array}$ & $\begin{array}{l}-0.0006^{* * *} \\
(0.00)\end{array}$ & $\begin{array}{l}-0.00067^{* * *} \\
(0.00)\end{array}$ \\
\hline
\end{tabular}

Note: $p$-values appear in parenthesis, and ${ }^{* * *},{ }^{* *},{ }^{*}$ denote significance at 1,5 and $10 \%$, respectively.

as the weight matrix $W$ the optimal one obtained according to the Moran's I test from the alternatives considered.

The results of the statistical tests are shown in Table 3. As can be seen, the Moran's / test (error) rejects the null hypothesis, indicating the existence of spatial structure in the residuals of the classical model. The Lagrange Multiplier tests corresponding both to the error lag and spatial lag model reject the null hypothesis, that is, both models improve the OLS estimation. In this case, the robust versions of the tests need to be considered. Nevertheless, these robust tests do not clarify which spatial model is the best option. This result is not common, but since there exists spatial dependence, both error lag model (M2) and spatial lag model (M3) are estimated, and the best option is chosen from checking the classical criteria of model selection.

The model (M2) presents a positive and significant $\lambda$ coefficient, showing a positive 138 spatial relationship among the errors. The significant coefficients of the model are the same as those in the classical model and with similar values. The tests indicate that residuals are homoskedastic and normal. The log likelihood test rejects the null hypothesis, revealing that the proposed model significantly improves the classical one. Additionally, the non-rejection of the null hypothesis from the Lagrange multiplier test shows that there are no alternative spatial structures excluded from the model. Regarding to the goodness of adjustment, the comparison of the alternative criteria (Akaike information, Schwarz, and log likelihood) leads to conclude that (M2) are better adjusted than the classical one for all the cases.

Model (M3) presents the spatial lag coefficient $\rho$ positive and significant, showing that neigbouring houses have similar rental prices. The significant variables are identical to the other models, and the diagnostic tests satisfy the required standard hypotheses. The 
Table 3. Goodness of fit measures and models validity tests.

\begin{tabular}{|c|c|c|c|}
\hline & $\frac{\mathrm{M} 1}{\mathrm{OLS}}$ & $\begin{array}{l}\frac{\mathrm{M} 2}{\text { Weight matrix: }} \\
2 \text { nearest neighbours }\end{array}$ & $\begin{array}{l}\mathrm{M3} \\
\text { Weight matrix: } \\
2 \text { nearest neighbours }\end{array}$ \\
\hline $\mathrm{R}^{2}$ & 0.63 & 0.61 & 0.66 \\
\hline Normality & $\begin{array}{l}1.35 \\
(0.50)\end{array}$ & & \\
\hline Log Likelihood & 39.76 & 43.12 & 42.83 \\
\hline Akaike.Information C. & -61.52 & -68.25 & -65.67 \\
\hline $\begin{array}{l}\text { Schwarz C. } \\
\text { Multicolineality test }\end{array}$ & $\begin{array}{l}-42.23 \\
31.24\end{array}$ & -48.96 & -44.24 \\
\hline Breusch-Pagan test & $\begin{array}{l}4.61 \\
(0.79)\end{array}$ & $\begin{array}{l}9.12 \\
(0.33)\end{array}$ & $\begin{array}{l}7.60 \\
(0.47)\end{array}$ \\
\hline Koenker-Bassett test & $\begin{array}{l}7.20 \\
(0.51)\end{array}$ & & \\
\hline \multicolumn{4}{|c|}{ Diagnostic for spatial dependence } \\
\hline Moran's I test (error) & $\begin{array}{l}3.17^{\star * \star} \\
(0.00)\end{array}$ & & \\
\hline Lagrange Multiplier (error) & $\begin{array}{l}6.08^{* *} \\
(0.01)\end{array}$ & & \\
\hline Robust LM (error) & $\begin{array}{l}0.44 \\
(0.50)\end{array}$ & & \\
\hline $\begin{array}{l}\text { Lagrange Multiplier } \\
\text { (spatial lag) }\end{array}$ & $\begin{array}{l}6.81^{* * *} \\
(0.00)\end{array}$ & & \\
\hline $\begin{array}{l}\text { Robust LM } \\
\text { (spatial lag) }\end{array}$ & $\begin{array}{l}1.17 \\
(0.27)\end{array}$ & & \\
\hline Likelihood ratio test $^{a}$ & & $\begin{array}{l}6.72^{* * *} \\
(0.00)\end{array}$ & $\begin{array}{l}6.15^{\star *} \\
(0.01)\end{array}$ \\
\hline Lagrange Multipliers test $^{\mathrm{b}}$ & & $\begin{array}{l}0.003 \\
(0.95)\end{array}$ & $\begin{array}{l}0.29 \\
(0.58)\end{array}$ \\
\hline
\end{tabular}

Note: p-values appear in parenthesis, and ${ }^{* * *},{ }^{* *},{ }^{*}$ denote significance at 1,5 and $10 \%$, respectively.

${ }^{a}$ Likelihood ratio test considers as alternative hypothesis the existence of differences between the proposed spatial model (spatial lag or lag error) and the classical model.

${ }^{b}$ Lagrange multiplier test propose as alternative hypothesis for model (M2) the existence of spatial lag trends from the proposed lag error model (M2); in the case of model (M3), it poses the existence of error lag tendencies from the proposed spatial lag model (M3).

goodness of adjustment criteria show that spatial error model (M2) is also better adjusted than model (M3).

Given the coefficients corresponding to the significant variables obtained with model (M2), houses located in windward have a price $61 \%$ higher than the rest $\left(e^{0.48}-1 \approx 0.61\right)$, this is, the humid slope in la Gomera is more appreciated by the rural tourist than the dry one. Nevertheless, while altitude affects positively to the rental price of the houses in leeward (100 additional meters of altitude increases rental price by $4.3 \%$ ), it influences negatively the rental price of the houses in windward (100 additional meters of altitude reduces the price by $4.3 \%-7 \%=-2.7 \%$ ). Regarding the structural variables, fireplace is the most valued attribute by the market. The existence of this facility in the rural houses in La Gomera increases the rental price by $24.4 \%\left(e^{0.218}-1 \approx 0.244\right)$.

\section{Conclusions}

This paper uses a hedonic price model to find the environmental rural tourist attributes that are most valued by the market in La Gomera Island, Spain. Hedonic pricing is an adequate tool to analyse the role of these factors in rural tourism since the spatial location of each lodging unit allows differencing its particular environmental characteristics. Other advantage of applying this methodology is that allows discriminating among the diverse attractions of a rural destination, showing which ones are relevant for the market, and to what extent. This information can be exploited by the public 
authorities or private managers to promote the most valuable attractions or to correct those attributes which are negatively appreciated or with null influence.

The results of the study case illustrate these advantages. Particularly, it was found that rural houses located out of the urban areas in La Gomera Island are significantly more valued by the market. Additionally, houses in the windward slope are more appreciated than the leeward slope, although the difference in the evolution of prices depending on the altitude in each slope shows that the market prefers to avoid extreme temperatures. These results indicate which locations are most adequate from the economical point of view, orienting about which new rural tourist areas can be more profitable. According to the findings, they would be those located in windward slope, away from urban areas, and not too high above sea level. Finally, it was also found that rural houses with fireplace are significantly more appreciated.

Nevertheless, the use of hedonic pricing in rural tourism also entails some limitations. One of them is that the model, due to its quantitative character, exclusively incorporates those factors susceptible to be measured, excluding those qualitative factors that are determinant in the rural tourism market. The enjoyment of landscape, the cultural heritage, events or gastronomy, are some of the main attractions of the rural tourism and are not included in the hedonic pricing model due to their nonquantitative nature. In order to overcome these obstacles, some proxy variables that represent these factors can be used, such as number of restaurants within a radius from the house. However, these variables do not reflect exactly the represented attribute.

The methodology used in this paper can be also applied to identify the most influencing environmental factors in other tourist destinations. To do this, the needed information must be available, that is, a representative sample of lodging units with their prices, lodging characteristics, as well as GIS maps with information about the geographical characteristics of the surroundings of the house.

\section{End note:}

1 There exist several ways of defining the connection among houses. The most common ones are whether or not the distance between them is smaller than a specific radius, or whether or not one house is included in the $k$ nearest neighbours of the house in question.

\section{References}

Anselin, L. (2005). Exploring spatial data with GeoDaTM: A workbook. UrbanaChampaign, IL: Spatial Analysis Laboratory, Department of Geography, University of Illinois

Bastian, C.T., McLeod, D.M., Germino, M.J., Reiners, W.A. and Blasko, B.J. (2002). Environmental amenities and agricultural land values: a hedonic model using geographic information systems data. Ecological Economics 20, 337-349

Geoghegan, J., Wainger, L.A. \& Bockstael, N.E. (1997). Spatial landscape indices in a hedonic framework: an ecological economics analysis using GIS. Ecological Economics 23, 251-264

Pulido-Fernández, J.I. (2008). Mercados de origen y destinos competidores del turismo rural español. In Síntesis (ed.) El Turismo Rural. Madrid: 287-325

Roberts, L. and Hall, D. (2003). Rural tourism and recreation: principles to practice. Oxon, UK: CABI Publishing

Rosen, S. (1974). Hedonic prices and implicit markets product differentiation in pure competition. Journal of Political Economy 82, 34-55.

Santana-Jiménez, Y., Suárez-Vega, R. and Hernández, J.M. (2011). Spatial and environmental characteristics of rural tourism lodging units. Anatolia 22(1), 89101

Sharpley, R. and Sharpley, J. (1997) Rural tourism. An introduction. London: International Thomson Business Press.

Thrane, C. (2005). Hedonic price models and sun-and-beach package tours: The Norwegian case. Journal of Travel Research 43, 302-308.

White, P.J. and Mulligan, G.F. (2002). Hedonic estimates of lodging rates in the four corners region. The Professional Geographer 54(4), 533-543. 